\title{
Influence of the Use of Capsaicin on the Storage of Rice Grain
}

\author{
Rasoazanakolona Voahanginirina \\ Technological Researches Department, National Center Applied for Rural Development, Antananarivo, Madagascar \\ Email: rasoazanakolona@yahoo.fr
}

How to cite this paper: Voahanginirina, R. (2018) Influence of the Use of Capsaicin on the Storage of Rice Grain. Open Access Library Journal, 5: e4833.

https://doi.org/10.4236/oalib.1104833

Received: August 13, 2018

Accepted: September 11, 2018

Published: September 14, 2018

Copyright (C 2018 by author and Open Access Library Inc.

This work is licensed under the Creative Commons Attribution International License (CC BY 4.0).

http://creativecommons.org/licenses/by/4.0/

\begin{abstract}
The storage of milled rice requires monitoring to achieve the goal promoted for its consumption: preserving the quality to feed effectively. Sometimes, however, contamination infiltrates under an atmosphere favoring the formation of weevils. A futile loss is created by the unexpected degradation. The effect of capsaicin on whitened rice Sitophilus o. weevils was monitored over time based on four different factors: the presence of chilli, the initial number of weevils present or introduced into milled rice, the weight of rice processed, and the variety of rice. The number of surviving weevils has been determined for up to six months. The Kruskall-Wallis test was performed on 34 samples of five varieties of milled rice. This showed a significant effect of chilli capsaicin action regardless of the factors considered. There are varieties of rice that respond well to treatment with capsaicin. Our experimentation proved that these are the varieties forming a high number of weevils at the beginning. The action of chilli capsaicin was also verified as an insect repellent and unappetizing, especially at the initial time that allowed to see leaking insects. It does not prevent the hatching of larvae, even if it has the capacity to kill weevils. The observed facts show that capsaicin is reserved for the protection of samples of whitened milled rice still devoid of contamination of larvae or adult weevils.
\end{abstract}

\section{Subject Areas}

Agricultural Science

\section{Keywords}

Rice weevil, Sitophilus oryzae (L), Capsicum sp., Capsaicin Effects, Pilokely Red Chilli Powder, Weight, Rice Variety

\section{Introduction}

Rice is the staple food of the Madagascans who must be kept vigilant to provide 
the desired sanitary quality. The rice storage problem usually occurs in a hot and humid climate when the population is unable to sell the offers to the market and the conditions of sale require a deposit of several months. Especially in areas where the relative humidity of the air and the heat are high, there is the birth of insects in the storage of rice. The noble objective of the seller to feed the population is distorted by a malice in the sales circuit caused by many factors: the atmosphere in the storage chamber and the hygroscopicity of milled rice compete. The storage of white rice is fragile and often difficult to solve when an infection manages to become embedded in the mass. To preserve its quality, collectors and consumer households are looking for their own method of preservation [1]. A good ventilation of the enclosure and storage in the shade in fresh medium are necessary conditions for the efficiency of its storage. Temperature and moisture are decisive factors to speed up or to delay grain deterioration. Bigger values accelerate insects and mould processing. According to the Burgess and Burrel diagram [2], a temperature of $15^{\circ} \mathrm{C}$ and grain moisture above $10 \%$ are sufficient conditions to cause the formation of insects. Moulds are found at temperature of $10^{\circ} \mathrm{C}$ (with the moisture of about $18 \%$ ). As high temperature is favourable to insects, insects are born from $20^{\circ} \mathrm{C}$ to $30^{\circ} \mathrm{C}$ when the moisture in the bag is only $5 \%$ to $10 \%$. Only, a temperature under $10^{\circ} \mathrm{C}$ and the moisture of grain at $15^{\circ} \mathrm{C}$ are good conditions for storage.

\subsection{Generalities on Sitophilus oryzae Motsch (in Malagasy, Koroka, Sakalavaloha) [3]}

It is a polyphagous insect, which perforates the seeds and lays in a hole in the grain furrow. Its white larva apod, has 4 stages all passed inside the grain of which it consumes all the albumen. Adult, it is brown to russet brown with two large red spots on the elytra; the head is prolonged by a rostrum and protonum provided with rounded punctuations arranged regularly, the wings are membranous able to the flight. The female of considerable longevity (6 to 7 months), lays in holes that it drills in the grains with its mandibles. Its fecundity is 300 eggs with a maximum of about 500; their incubation lasts 10 to 15 days. It drills a hole in the kernels and deposits a single egg. After laying, the hole is closed with hard secretion. The eggs are deposited in the grains of the warehouses. After three larval stages ( 15 to 30 days), the larva pupates. The imago emerges after a week. Sitophilus $s p$. is a primary type pest, which represents a species exclusively adapted to life in grains, within which it performs the majority of its development cycle in "hidden form", invisible to direct observation. At an advanced stage of the infestation, especially on the shelled products, there is the presence of powder and a notable loss of weight.

\subsection{Brief Presentation of Capsicum sp.}

The dry red chilli of Capsicum sp. [4] is traditionally used to preserve milled rice from weevil degradation in rural and urban Madagascan households [5]. This pepper is also used in cereals and dry legumes in the form of powder mixed with 
inert matter such as ash, or in spray solution mixed with a few cloves of garlic crushed and sticky solution in other countries.

Capsaicin has five families [6]: capsaicin (base), dihydro-, nor-, homo-, and homo-dihydro-capsaicin. Capsaicin is the most pungent of the five families, but also the most concentrated in active ingredient. The red pepper of Capsicum sp. contains more this basic capsaicin, an alkaloid recognized by its pungent principle. It contains about $0.065 \%$ of capsaicin on dried matter [7]. The strength of its pepper is $16,000,000$ units Scoville according to the pharmacologist Wilbur Scoville; it is the strongest one among the 5 families.

The level of capsaicinoids can vary due to the environment where the plant is grown in and the location of the fruit on an individual plant [8] [9] (Figure 1).

Exposure to capsaicin causes bronchoconstriction in humans and animals [10]. The LD50 oral lethal dose causing death of $50 \%$ of mice is $60-75 \mathrm{mg} / \mathrm{kg}$ [11].

The aim of this study is to better define the qualities offered by capsaicin and to search for more appropriate valuation techniques for this type of alkaloid. (Figure 2).

\section{Materials and Methods}

\subsection{Biological Materials}

\section{Plant material}

- Breaded rice weighing from $5 \mathrm{~g}$ to $68 \mathrm{~g}$ of five varieties of white rice: MR10240, MR10253, MR10214: irrigated rice, X1834: aromatic irrigated rice; FOFIFA159: rainfed rice.

They were all received at FOFIFA, bleached and kept for 3 months before the experiment. They are all translucent varieties with white belly, but the number of white-bellied grains varies from one variety to another.

- Fine powder of red chilli Capsicum sp., bought at the market.

\section{Animal material}

- Live succulents Sitophilus o.: 2 to 30, derived from contaminated milled rice. They were counted with naked eyes by pouring the sample on a spread large receptacle as a tray for winnowing rice.

\section{Materials and supplies}

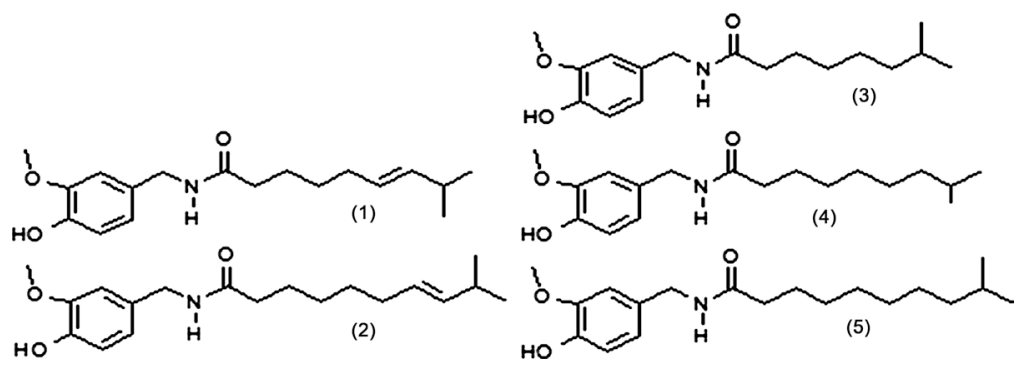

Figure 1. Developed chemical formula of the 5 alkaloids of chilli. (1) capsaicin, (2) homo-capsaicin, (3) nor-dihydro-capsaicin, (4) dihydro-capsaicin,

(5) homo-dihydro-capsaicin. 


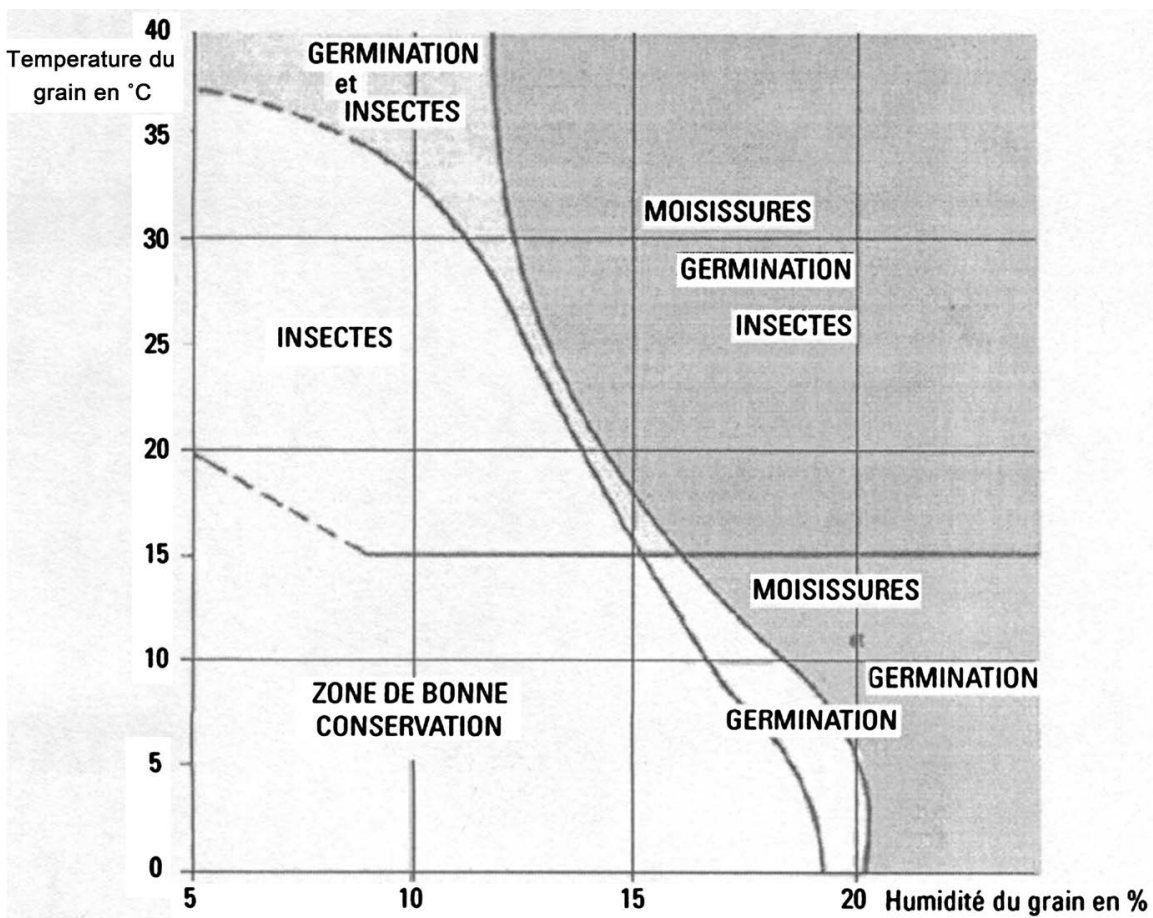

Figure 2. Burgess and Burrel Diagram [2].

\section{Plastic bag of identical format}

The weevils were enclosed in a knotted plastic bag containing milled rice. The respective number of live weevils introduced into the bag were 2, 5, 10, 20, 30 weevils (Table 4). Sitophilus o. weevils are parasites feeding on rice albumen.

To better understand the insecticidal action of Capsicum sp. on the preservation of milled rice, Sitophilus o. live weevils were introduced into milled rice samples and the number of survivors under the chilli powder treatments was monitored. The experiment was carried out in the laboratory of the Technological Research Department during the hot season to promote hatching.

\subsection{Methods}

General conditions: The monitored parameters include the presence of chilli pepper, the time, the initial number of weevils present or introduced into the milled rice, the weight of rice treated, the variety of rice. The average ambient temperature was $25^{\circ} \mathrm{C}$. The treatment times that were the subject of our experiment were respectively $\mathrm{t} 1=0, \mathrm{t} 2=30, \mathrm{t} 3=67, \mathrm{t} 4=110, \mathrm{t} 5=150, \mathrm{t} 6=180$ days, according to the acronyms shown on the graphs. The number of repetitions made was 5 to 14 . The total number of samples studied was 34 from the 5 varieties mentioned above.

- Rice: Weight of the rice. The weight of the rice varied according to a respective weight of $5 \mathrm{~g}, 30 \mathrm{~g}, 45 \mathrm{~g}, 68 \mathrm{~g}$, but the chilli powder was fixed at a dose of one teaspoonful for all experiments.

- Witness: A white rice sample without capsaicin (without chilli) was made to separate the effects of chilli and lack of oxygen. 
- Statistical Analysis: All data were entered and processed in SPSS 10, version 10.0.7 (June 2, 2000). The normality test and the Kruskal-Wallis test were applied to evaluate the significance of the averages.

\section{Results}

The effect of the various parameters (presence or absence of chilli, time, varieties, initial number of weevils) will be explained in various paragraphs of this section to justify the mode of capsaicin action in our samples (Figure 3 ).

\section{Effect of the presence of chilli on the number of live weevils}

For the rice without chilli, the slope is gentle, ranging from 2 to 0.5 , proving that the number of living weevils has changed little, while chilli rice has shown a stronger (3.5 to 0.5 ) drop of live weevils, explaining the notable action of the pepper (Graph 1).

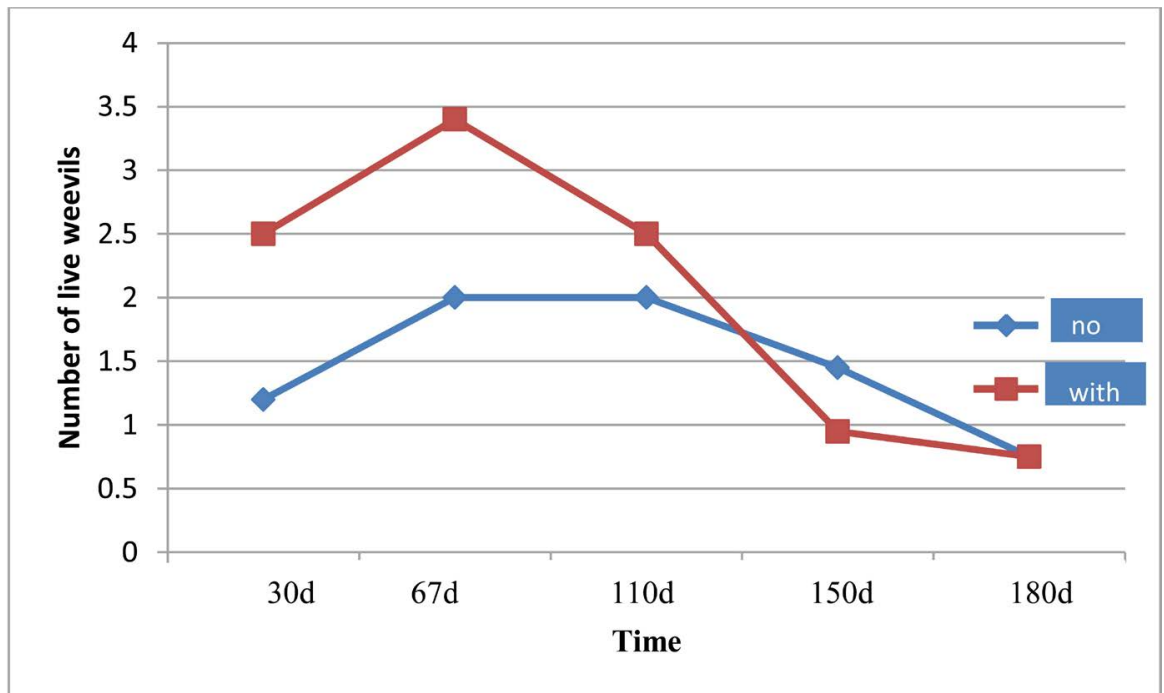

Figure 3. Average number of live weevils for treatments upper square and lower square chilli.

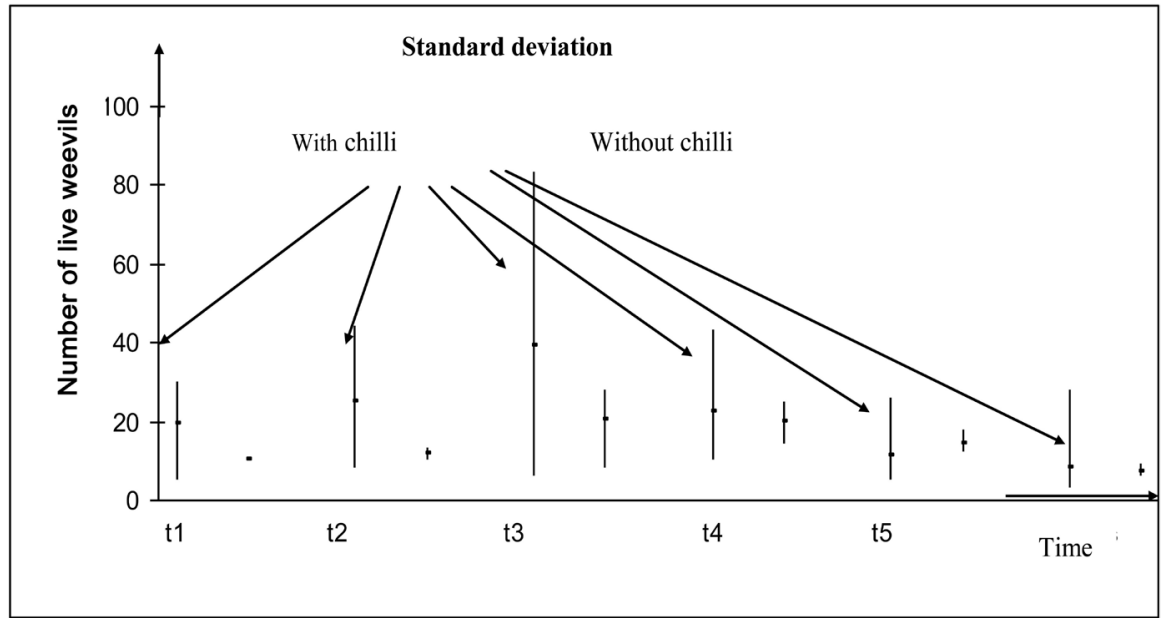

Graph 1. Variation in standard deviation for treatment with and without chilli. 
Interpretation: The small discrepancy mentioned for treatment without chilli means a small variation in the proportion of live.

In other words, dead weevils are almost non-existent. The air was not asphyxiated by the alkaloid and the weevils could live longer in the plastic bag without chilli. In the case of chilli treatment, the effect of chilli was evident because the gap between the minimum and the maximum was always greater, mentioning that dead weevils have increased for a given time $t$.

Impact of time on the number of live weevils

Two weevils were introduced at the initial time. A significant gradual increase in the proportion of weevils up to 67 days (maxima) was observed. A slight non-significant decrease was noted between 67 days and 110 days (grouping $b$ to bc). The decline was accentuated in the 150 days (grouping ac), then 180 days (group ad).

The Kruskal-Wallis test indicated a significant difference (probability $=0.00$ ) in the proportion of living weevils treated with chilli powder over time: Table 1, schematized in Figure 4.

Interpretation: The increase in the proportion of live weevils up to 67 days showed that it was not yet a sensitive effect of chilli. The weevils hatched until this time and could still live because the pressure of the gas emanated from

Table 1. Significance of the proportion of live weevils (lw) as a function of time.

\begin{tabular}{cccc}
\hline Time & Nb days & Nb Groupement & lw \\
\hline t1 & 0 & a & 1.000 \\
t2 & 30 & ac & 2.248 \\
t3 & 67 & $\mathrm{~b}$ & 3.252 \\
t4 & 110 & bc & 2.482 \\
t5 & 150 & ac & 1.608 \\
t6 & 180 & ad & 1.128 \\
Probability $p$ & & & 0.00 \\
\hline
\end{tabular}

$\mathrm{lw}=$ live weevils.

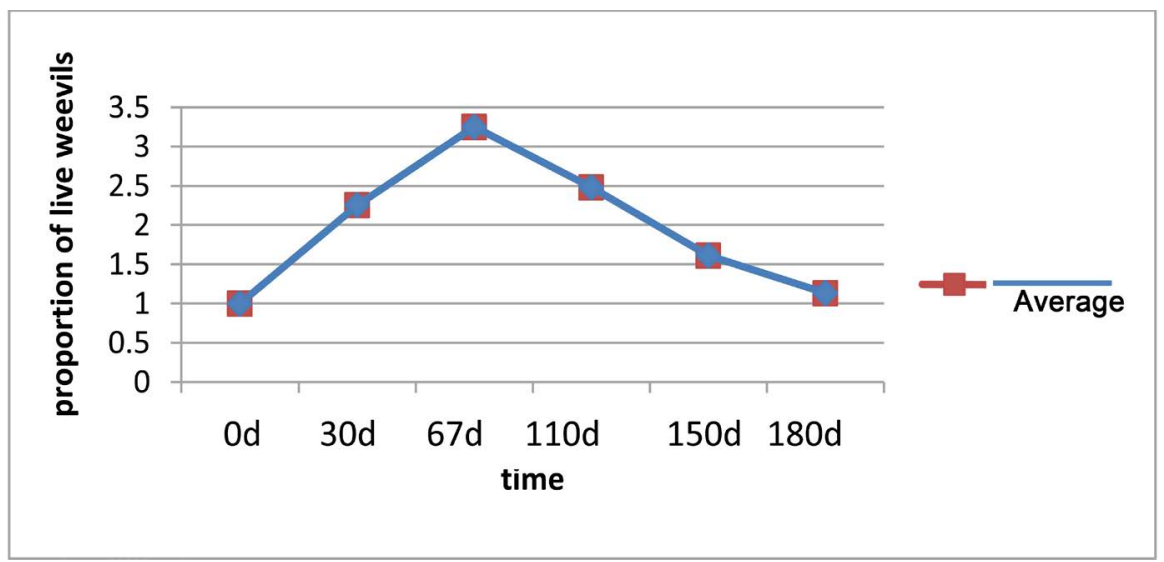

Figure 4. Variation in proportion of live weevils as a function of time for all varieties. 
capsaicin was still low (low concentration of the gaseous alkaloid in the enclosure). The oxygen has not yet been completely exhausted in the bag and the ambient temperature was still favourable for hatching of weevils.

The attack was clearer and clearer from the 110 days. The weevils have grabbed the asphyxiating odor and were dead.

The action of $\mathrm{CO}_{2}$ and that of the smell of capsaicin were added to promote this death. At 180 days, the number of weevils found was about the same; all weevils born over time were dead as a result. The remaining number was identical to the number when the weevils were enclosed in the bag.

Effect of initial rice weight

Two weevils were introduced at the initial time (Table 2).

Table 2. Significance of proportion of live weevils by weight of treated rice.

\begin{tabular}{ccccccc}
\hline Weight (g) of rice & N repetitions & $30 \mathrm{~d}$ & $67 \mathrm{~d}$ & $110 \mathrm{~d}$ & $150 \mathrm{~d}$ & $180 \mathrm{~d}$ \\
\hline 5 & 5 & $1.136 \mathrm{a}$ & $1.060 \mathrm{a}$ & $0.676 \mathrm{a}$ & $0.58 \mathrm{a}$ & $0.41 \mathrm{a}$ \\
$\mathbf{3 0}$ & 12 & $3.759 \mathrm{~b}$ & $4.712 \mathrm{~b}$ & $3.508 \mathrm{~b}$ & $2.77 \mathrm{~b}$ & $2.01 \mathrm{~b}$ \\
$\mathbf{4 5}$ & 13 & $1.528 \mathrm{a}$ & $3.012 \mathrm{~b}$ & $2.380 \mathrm{a}$ & $0.91 \mathrm{a}$ & $0.59 \mathrm{a}$ \\
68 & 5 & $0.974 \mathrm{a}$ & $1.988 \mathrm{a}$ & $1.680 \mathrm{a}$ & $1.24 \mathrm{a}$ & $0.96 \mathrm{a}$ \\
$\mathrm{p}$ & & 0.027 & 0.022 & 0.009 & 0.004 & 0.002 \\
\hline
\end{tabular}

The proportions corresponded to the ratio between the number at final time and initial time of live weevils.

A significant difference was observed over time, regardless of the weight of treated rice $(\mathrm{p}<0.05)$. This significance was more and more marked towards the final time. The evolution of the number of insects living along time generally showed the same pace for all studied weights: decreased after 67 days of storage, its maximum point.

Interpretation: For an initial weight of treated rice equal to $5 \mathrm{~g}$, weight showing that there is not enough food for the weevils, the number of live weevils was down to 0.41 , i.e. the number of dead weevils increased, while for a weight of $68 \mathrm{~g}$ of rice, the proportion of live weevils (0.96) was almost the same as the initial time (0.974), the values were almost unchanged.

- It was the same for a weight of $30 \mathrm{~g}$ of initial sample, where the proportion of live weevils found at the final time was double compared to the initial time, expressing a much larger food to consume, allowing them to survive.

The possible explanation is that weevils can still live when they have enough food to consume. The greater is the area of contact of the chilli with the rice, the greater is the amount of alkaloid emitted, making easier its intervention.

- For a weight of rice $45 \mathrm{~g}$, the proportion of live weevils was lower than in the case of $30 \mathrm{~g}$, with a final proportion of 0.59 at 180 days. The good tightness of the enclosure more enriched in $\mathrm{CO}_{2}$ can be the cause.

We can follow the number of weevils born over time in Table 3:

weevils born $(\mathrm{t})=$ live weevils $(\mathrm{t})$ - weevils $(\mathrm{t} 1)$ 
Table 3. Number of weevils born over time.

\begin{tabular}{cccccccc}
\hline Weight $(\mathrm{g})$ of rice & Nrepetition & $\mathrm{w}(0 \mathrm{~d})$ & $\mathrm{w}(30 \mathrm{~d})$ & $\mathrm{w}(67 \mathrm{~d})$ & $\mathrm{w}(110 \mathrm{~d})$ & $\mathrm{w}(150 \mathrm{~d})$ & $\mathrm{w}(180 \mathrm{~d})$ \\
\hline $\mathbf{5}$ & 5 & 1 & 0.136 & 0.060 & 0 & 0 & 0 \\
$\mathbf{3 0}$ & 12 & 1 & 2.759 & 3.712 & 2.508 & 1.770 & 1.010 \\
$\mathbf{4 5}$ & 13 & 1 & 0.528 & 2.012 & 1.380 & 0 & 0 \\
$\mathbf{6 8}$ & 5 & 1 & 0 & 0.988 & 0.680 & 0.240 & 0 \\
$\mathbf{p}$ & & & 0.027 & 0.022 & 0.009 & 0.004 & 0.002 \\
\hline
\end{tabular}

According to our results, most of the weevils born died after 180 days of treatment.

Also, we can say that survivors were almost non-existent and that hatching was usually attacked by capsaicin. Only, for the weight of $30 \mathrm{~g}$, there is still a number of living equal to that of the initial time (t0) (Figure 5).

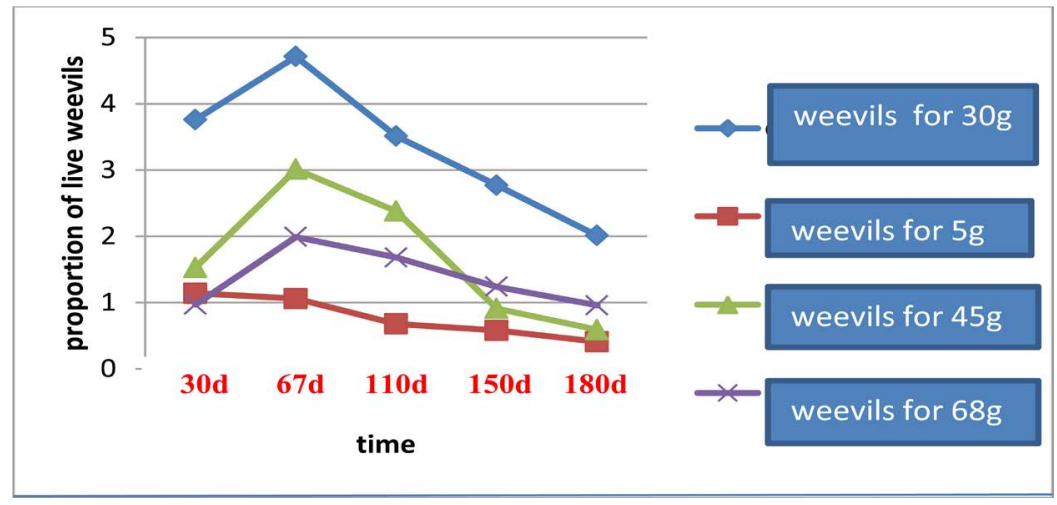

Figure 5. Proportion of live weevils for varied rice weights.

\section{Incidence of the initial number of introduced weevils}

There was a significant effect of the number of introduced weevils on the proportion of live weevils. For small numbers of introduced weevils, the proportion of live weevils was even stronger by 3 times to 1.3 times at the end of the observation.

For a number of introduced weevils equal to 10 or 20 , the proportion of alive weevils at 110 days was identical (group "a"), although in slight rise. At 180 days both cases (10 and 20 introduced weevils) marked the same group "a", but a decrease in half compared to 110 days was noted (Table 4).

Table 4. Significance of the proportion of live weevils according to the number of introduced ones.

\begin{tabular}{ccccccc}
\hline weevils (N) & Repetitions & $\mathbf{3 0 \mathrm { d }}$ & $\mathbf{6 7 \mathrm { d }}$ & $110 \mathrm{~d}$ & $150 \mathrm{~d}$ & $180 \mathrm{~d}$ \\
\hline $\mathbf{2}$ & 5 & $3.000 \mathrm{~b}$ & $6.400 \mathrm{~b}$ & $3.900 \mathrm{~b}$ & $4.200 \mathrm{~b}$ & $3.300 \mathrm{~b}$ \\
$\mathbf{5}$ & 5 & $2.880 \mathrm{~b}$ & $4.720 \mathrm{c}$ & $5.760 \mathrm{~b}$ & $2.160 \mathrm{c}$ & $1.280 \mathrm{c}$ \\
$\mathbf{1 0}$ & 14 & $2.364 \mathrm{~b}$ & $2.807 \mathrm{c}$ & $1.957 \mathrm{a}$ & $1.357 \mathrm{c}$ & $0.721 \mathrm{a}$ \\
20 & 5 & $1.890 \mathrm{a}$ & $2.080 \mathrm{c}$ & $1.590 \mathrm{a}$ & $2.080 \mathrm{c}$ & $0.740 \mathrm{a}$ \\
$\mathbf{3 0}$ & 6 & $0.907 \mathrm{a}$ & $1.117 \mathrm{a}$ & $0.715 \mathrm{a}$ & $0.512 \mathrm{a}$ & $0.333 \mathrm{a}$ \\
Probability p & & 0.03 & 0.027 & 0.001 & 0.002 & 0.001 \\
\hline
\end{tabular}

$\mathrm{N}$ : number of introduced weevils. 
For 30 introduced weevils, the decrease in proportion was the fastest, due to insufficient food and air. It follows that weevils died faster if they are numerous in the same bag, to consume the same portion of food. The reasons were various, namely, the decrease in the proportion of food consumed by weevil, the atmosphere in the enclosure more enriched in $\mathrm{CO}_{2}$ because the oxygen was consumed, the action of the capsaicin reinforced (asphyxiant and deleterious effect).

In the majority of cases, the greater was the number of introduced weevils, the lower was the proportion of living ones, because the atmosphere was saturated with carbon dioxide, and the emitted alkaloid also played a favourable role. The lifespan of a weevil is about five months; therefore, the proportion observed at 5 months corresponded largely to weevils having finished their life cycle. In all cases, the rice grain has acquired eggs of weevils in the previous stage. These were hatched under the conditions of our treatment (Figure 6).

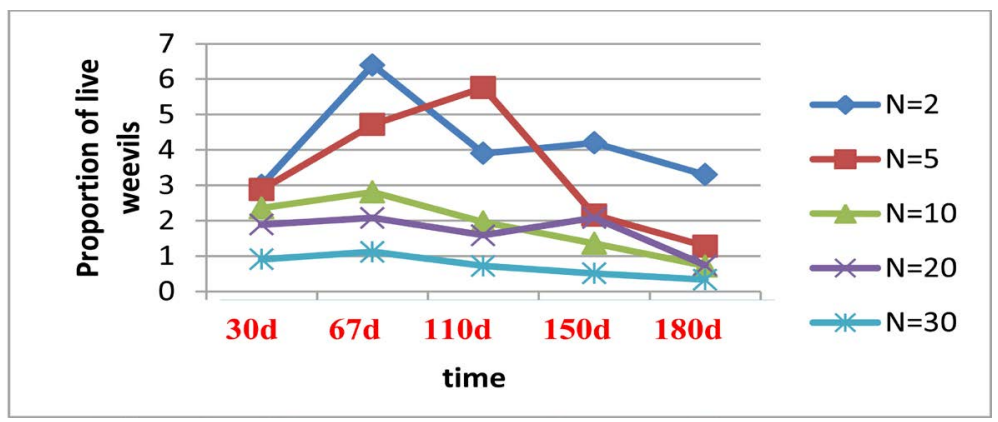

Figure 6. Proportion of live weevils for given numbers of introduced weevils.

\section{Incidence of the rice variety}

Most of our varieties were translucent grains with white belly, so of low hardness according to our previous studies [12]. There was a significant difference between the varieties on the proportion of live weevils over time, except for the 67 days. At this time, the number of living ones was at their maximum according to the parameters of our study. Weevils were usually attacked only after a two-month incubation period.

- About variety MR10240, at 30 days of treatment, there has been already a decrease in the number of live weevils (Table 5), probably due to a leak of weevils, then this increased after 67 days, due to an egg hatch; this proportion quadrupled at 110 days. Then, it dropped to a ratio of 0.86 at 180 days compared to departure.

Table 5. Significance of the proportion of live weevils according to the variety of rice.

\begin{tabular}{ccccccc}
\hline Variety & Nrepetition & $30 \mathrm{~d}$ & $\mathbf{6 7 \mathrm { d }}$ & $110 \mathrm{~d}$ & $150 \mathrm{~d}$ & $180 \mathrm{~d}$ \\
\hline MR10240 & 9 & $0.919 \mathrm{a}$ & $2.893 \mathrm{a}$ & $3.656 \mathrm{a}$ & $1.440 \mathrm{a}$ & $0.860 \mathrm{a}$ \\
MR10253 & 9 & $1.133 \mathrm{a}$ & $1.733 \mathrm{a}$ & $1.200 \mathrm{~b}$ & $0.960 \mathrm{a}$ & $0.560 \mathrm{a}$ \\
MR10214 & 6 & $2.417 \mathrm{a}$ & $3.588 \mathrm{a}$ & $2.265 \mathrm{a}$ & $1.050 \mathrm{a}$ & $0.810 \mathrm{a}$ \\
X1834 & 5 & $3.000 \mathrm{~b}$ & $6.400 \mathrm{a}$ & $3.900 \mathrm{a}$ & $4.200 \mathrm{~b}$ & $3.300 \mathrm{~b}$ \\
FOFIFA159 & 5 & $5.690 \mathrm{~b}$ & $3.080 \mathrm{a}$ & $1.520 \mathrm{a}$ & $1.160 \mathrm{a}$ & $0.850 \mathrm{a}$ \\
Probability p & & 0.015 & n.s. & 0.034 & 0.013 & 0.007 \\
\hline
\end{tabular}


- In the case of the variety MR10253, the proportion decreased after 67 days, and at 180 days, the number of live ones was almost half of the departure.

- For X1834 and FOFIFA159, there was already at 30 days time a net increase in the proportion of living weevils (Table 5).

- In the case of FOFIFA159, this then steadily decreased until 180 days. The proportion of live weevils in this last variety reached 0.15 less than at $\mathrm{t} 1$ ( 30 days).

- Concerning varieties MR10214 and FOFIFA159, at the final time 180 days were recorded the highest difference of proportions (2.417 - 0.81 and 5.69 0.85), related to 30 days. The variety FOFIFA159 was the most sensitive to treatment (Figure 7).

Interpretation: Chilli was used in FOFIFA159 as weevil growth regulator, once hatched, weevils tended to die little by little under the action of chilli.

For X1834, the number of live weevils tripled at 30 days of storage and increased six fold at 67 days. It has slightly decreased after this time, but the proportion of living at the final time was still triple of the departure. This variety responded little to the action of the chilli; it is an aromatic variety, so probably the weevils that it sheltered appreciated its aromas (2-acetyl, 1-pyrroline) of popcorn [13], which would have an attenuating role of the smell of the alkaloid. As a result weevils were still eating rice albumen. This variety seemed here very sensitive to the attacks of the weevils.

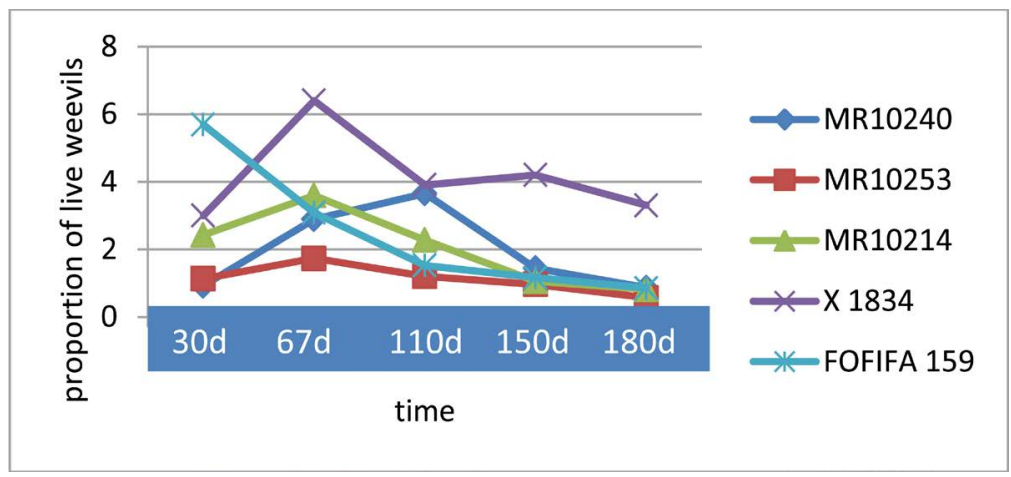

Figure 7. Variation of proportion of live weevils according to varieties.

\section{Number of dead weevils according to different varieties}

There was a significant difference in the number of dead weevils over time according to the different varieties studied (Table 6): probability $\leq 0.05$. Groups obtained according to the Mann-Whitney test showed three or four types of grouping (A, B, C, D) for each period.

For MR10253, the number of dead weevils was already at maximum at 67 days (18.72) proving its ease of treatment at an early time. Young weevils born and attacked by chilli powder did not generally survive after 67 days of survival, so was noted an increase in the number of deaths from this time. At the period of 110 days, the number of dead weevils was maximum for two varieties: MR10214 (26.33: grouping “ $A$ ”) and MR10240 (19.67: grouping “ $B$ ”). But at the final time 
Table 6. Kruskal-Wallis test on the number of dead weevils.

\begin{tabular}{cccccccccccc}
\hline VARIETY & N & $30 \mathrm{~d}$ & G & $67 \mathrm{~d}$ & G & $110 \mathrm{~d}$ & $\mathrm{G}$ & $150 \mathrm{~d}$ & $\mathrm{G}$ & $180 \mathrm{~d}$ & $\mathrm{G}$ \\
\hline FOFIFA159 & 5 & 10.08 & A & 19.2 & ABC & 18.92 & AB & 21.12 & A & 14.4 & A \\
MR10214 & 7 & 5.73 & B & 24.73 & A & 26.33 & A & 13.35 & B & 4.04 & B \\
MR10240 & 6 & 4.17 & B & 10.5 & B & 19.67 & B & 9.5 & C & 4.67 & B \\
MR10253 & 5 & 12 & A & 18.72 & AC & 11.52 & C & 7.68 & C & 6.24 & C \\
X1834 & 5 & 1.44 & C & 7.44 & D & 7.44 & D & 9.6 & C & 5.28 & C \\
Probability & & $<0.001$ & & 0.001 & & $<0.001$ & & $<0.001$ & & 0.002 & \\
\hline
\end{tabular}

$\mathrm{N}$ : number of repetitions, G: group of membership, $\mathrm{d}=$ days, probability $\mathrm{p}<0.05$ : significant.

180 days, these two varieties were similar (same grouping "B"). MR10253, MR10240 and X1834 knew the same grouping "C" at 150 days.

For the maximum number of dead weevils found at 150 days (case of FOFIFA 159 and MR10214), we recognized the combination of the period of life of a weevil (the death of aged weevils) and the attack of chilli.

\section{Discussion}

The results showed significant effect of chilli in the weight, the varieties of rice, the number of introduced weevils into the treated rice, the comparison of treated rice with chilli and without chilli.

As variety effect, the variety FOFIFA159 and MR10214 were the most sensitive to chilli treatment and X1834, an aromatic rice was very little favourable to that. Concerning weight of rice, for a small quantity of rice, there was not enough food for the weevils, the number of live weevils was down to 0.41 , i.e. the number of live weevils decreased; so, a small quantity of rice was generally more sensitive to the decrease of live weevils than a big one, the reason was that weevils could still live when there was more food to consume. For the number of introduced live weevils, few numbers of it (such as 2 or 5 weevils) had less favourable effect. The greater was the number of introduced one, the more the weevils died quickly. Indeed, their food was insufficient, the atmosphere was enriched in $\mathrm{CO}_{2}$ and the action of capsaicin was reinforced. Along the time, dead weevils gave significant difference according to the varieties.

Those results well agreed with the expected role of the chilli in the rice grain. Its alkaloid eliminates natural predators. It has been verified that Capsicum $s p$. is used as an insecticide and a repellent in ecological control methods [14]. Previous work has shown that capsaicinoids has also antifungal properties against Fusarium semitectum, a primary cause of predisposal seed mortality in chile pepper [15] and also against anthracnose, Colletotrichum capsici [16]. We suggested that probably capsaicin concentration was genotype and its high concentration inhibited the predator and the fungi. Capsaicin is pungent, bronchoconstricting, and toxic with the letal dose $60-75 \mathrm{mg} / \mathrm{kg}$ of mice. It possessed the immunosuppressive activities having ability to inhibit bacterial growth and 
platelet aggregation [17].

The time required to kill Sitophilus 0 . weevils is on one side dependent on the activity of the grain-parasite complex, according to the Burgess-Burrel diagram [2]; this activity depends on the humidity and the temperature of the grains. To eliminate weevils, a grain temperature below $15^{\circ} \mathrm{C}$ and a sufficiently dry grain (maximum moisture 15\%) are required. Thus, the product to be preserved must be put in a dry and watertight place. Fresh silo storage combined with chilli powder treatment could be more effective: death would be faster. Keeping the grain temperature above $15^{\circ} \mathrm{C}$ prevents rapid death of weevils. This fact makes formidable weevil multiplication and mold formation in a tropical climate where the grain temperature can reach $25^{\circ} \mathrm{C}$ and its humidity $15 \%$.

Sitophilus $o$. weevils are less sensitive to oxygen deficiency than to chilli pepper. A significant decrease in the proportion of live weevils was noted beyond 67 days. More or less leaks have occurred through the plastic bag, showing that the weevils escaped the asphyxiating odor of capsaicin.

Other natural treatments are likewise possible; for example, yellow pea protein extract [18]. It is an extract with toxic properties and insect repellents for several insect pests of stored food products and possesses stable insecticidal activity. The high protein extract is more active and at a concentration of $0.1 \%$, it eliminates the rice weevil, and reduces by $70 \%$ populations of Red Cucujid and Red Tribolium of Flour. The toxicity is 20 to 100 times higher than the pea flour itself (patent 5, 955.082 in the United States, patent 2, 278.501 in Canada).

\section{Conclusions}

The treatment done along time was effective. The insecticidal property of chilli capsaicin was verified because weevils were dead. For the comparison with/without chilli, the effect of the treatment was clear (high standard deviation between maxima and minima). The number of introduced weevils, the crop type of rice and the weight of milled rice to be treated gave significant differences on the treatment. The optimal dose found was $45 \mathrm{~g}$ of rice for a teaspoonful of pepper. However, the reaction was slow.

The traditional treatment with chilli powder was slower since it usually took more than 3 months to observe the effectiveness of the treatment, i.e. the insect repellent and anti-appetizing effects.

This property was especially noticed at the beginning. Traditional treatment can be reserved for rice that is still healthy and free of weevils contamination. It does not prevent the hatching of the larvae. Its action requires a strong dose towards Sitophilus $o$. A concentration of capsaicin extract is therefore necessary to increase its effectiveness. An enrichment of the alkaloid is a viable solution. Natural insecticide products have a largely limited harmfulness compared to the chemicals that exist on the market; those have health risks more pronounced for the population. Also, for domestic purposes, it is advisable to turn to the development of the natural products. 


\section{Conflicts of Interest}

The author declares no conflicts of interest regarding the publication of this paper.

\section{References}

[1] de Groot, I. (2004) Protection of Stored Grains and Pulses.

[2] ACT (2002) Agronomist Handbook. GRET.

[3] Ministry of Agriculture and Ministry of Scientific Research (1992) Crop Protection Data Sheet. Sheet N¹6/1992, GTZ.

[4] http://tomodori.com/

[5] Ratsizafy, C. (1987) Aspects du stockage des graines en milieu rural de Fianarantsoa. Provincial Plant Protection Service in Fianarantsoa, Directorate of Plant Protection.

[6] Wikipedia (2009) Capsaicin, the Free Encyclopedia. Wikimedia Foundation Inc., San Francisco.

[7] ANSM (2008) Capsicum annum and Homeopathic Preparation. French Pharmacopea.

[8] Zewdie, Y. and Bosland, P.W. (2000) Evaluation of Genotype, Environment, and Genotype-by-Environment Interaction for Capsaicinoids in Capsicum annuum L. Euphytica, 111, 185-190. https://doi.org/10.1023/A:1003837314929

[9] Zewdie, Y. and Bosland, P.W. (2000) Pungency of Chile (Capsicum annuum L.) Fruit Is Affected by Node Position. HortScience, 35, 1174

[10] Brodeur, J., Beausoleil, M., Andrée Roy, L. and Lavigne, J. (2003) Riot Agents B-3 Section. National Institute of Public Health of Quebec, Montreal Public Health Department.

[11] Glinsukon, T. (1980) Acute Toxicity of Capsaicin in Several Animal Species. Toxicon, 18, 215-220. https://doi.org/10.1016/0041-0101(80)90076-8

[12] Rasoazanakolona, V. (2010) Impacts négatifs de quelques facteurs environnementaux, structuraux et morphologiques sur la qualité du grain de riz. Doctorate, Faculty of Sciences, University of Antananarivo, Antananarivo.

[13] Sharp, R.N. (1986) Quality Evaluation of Milled Aromatic Rice from India, Thailand, and the United States. Journal of Food Science, 51, 634-636.

[14] Grainge, M. and Ahmed S. (1988) Handbook of Plants with Pest-Control Properties. Resource Systems Institute, East-West Center, John Wiley \& Sons, Honolulu.

[15] Tewksbury, J.J., Reagan, K.M., Machnicki, N.J., Carol, T.A., Haak, D.C., Calderón, Peñaloza, A.L. and Levey, D.J. (2008) Evolutionary Ecology of Pungency in Wild Chillies. Proceedings of the National Academy of Sciences of the United States of America, 105, 11808-11811. https://doi.org/10.1073/pnas.0802691105

[16] Kraikruan, W., Sangchote, S. and Sukprakarn, S. (2008) Effect of Capsaicin on Germination of Colletotrichum capsici Conidia. Kasetsart Journal (Natural Science), 42, 417-422.

[17] Saxena, A., Raghuwanshi, R., Gupta, V.K. and Singh, H.B. (2016) Chilli Anthracnose: The Epidemiology and Management. Frontiers in Microbiology, 7, 1527.

[18] Agriculture and Agri-Food Canada (2007) Natural Pea Insecticides. Flintbox Innovation Network Inc., Ottawa. 